\title{
CHANGES OF THYROID ACTIVITY IN THE RAT IN OLD AGE
}

\author{
F. VERZAR, M.D., AND V. FREYDBERG, B.S.
}

\section{(From the Physiological Laboratory of the University of Basel, Basel, Suitzerland)}

\begin{abstract}
A DECREASE of the activity of the thyroid in old age has often been mentioned in humans. Anatomic involution was described $(5,7,10)$ and this was related to the decrease of basal metabolism in old age (2). Also a decrease of plasma iodine (8) and an increase of serum cholesterol (3) was observed. The uptake of $I^{131}$ in the thyroid in old age has been studied by Quimby, Werner, and Schmidt (11) and this was related to the function of the kidney $(1,6,9)$ while Skanse (12) found no significant differences.

Since all these, partly contradictory, works were performed on humans we have now studied the problem of whether the thyroid activity changes with age in rats, in the "old age colony" of our laboratory, where all animals are of the same breed and are kept under identical conditions.
\end{abstract}

\section{METHODS}

Rats were injected intraperitoneally with 25 microcuries of $\mathrm{I}^{131}$ (without carrier), dissolved in $0.25 \mathrm{ml}$. of physiologic saline solution. Eighteen to 24 hours later the thyroid region of the rats was tested for radioactivity by means of a TCG2 Geiger counter (Tracerlab). The procedure was identical with that previously used in this laboratory $(13,14)$. The radiation values over the thyroid region were measured in series after 24,61, 134, and

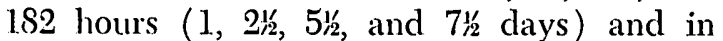
series II after 22-24, 69-71, 110-114 and 165 hours (1, 3, 412, and 7 days).

Immediately prior to the radioactivity measurements the animals were anesthetized with ether, using a glass bulb. The excitation period is very short when a massive dose is given. The anesthesia was continued during the estimation, which lasted about three minutes. This procedure was then repeated every 24 hours, or in some instances after longer periods, until approximately the fourteenth day after the injection of $\mathrm{I}^{\mathrm{si}}$, at which time the radiation count approaches zero. It is

Submitted for publication April 6, 1955. of course possible that the thyroid at the end of this period may still contain small amounts of $\mathrm{I}^{131}$ the radiation of which is too small to penetrate the skin. The values measured were always corrected for physical decay and for the background count. The reliability of this method for rats was proven in previous publications $(13,14)$. The radiation values during a period of several days follow each other on a continuous line and single values are well reproduced in immediately following measurements. In former work, the uptake was studied from the first hours after injection, but this was not necessary with regard to the present problem.

In a number of animals the excretion of iodine in the urine was also measured. For this purpose the rats were placed in individual glass cages. The urine was collected and the water used to wash the cage added to the sample. All urine samples were made up to $50 \mathrm{ml}$. with water and an aliquot used for radiation measurement.

The estimation was made by evaporating 1. $\mathrm{ml}$. of the urine sample to dryness at $95 \mathrm{C}$. in a small planchet. The radiation was measured and compared with equal quantities of the originally injected solution, which contained 25 microcuries in $0.25 \mathrm{ml}$. volume and expressed in percentage of the latter.

TABIE 1. Comparison of [131 IN The First 24 Hour URINE WITH TWO METHODS.

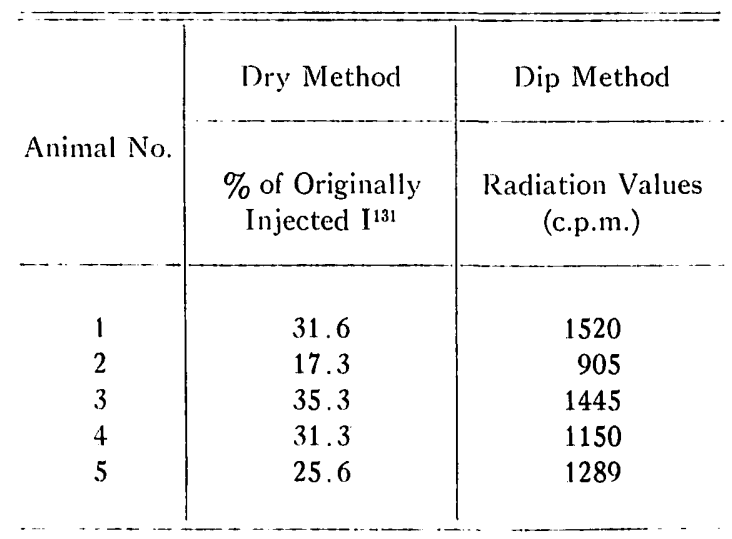


Another procedure for measuring the urinary radioactivity was also employed. For this assay a dip Geiger counter (TCG5) was used on urine samples which had been diluted to $50 \mathrm{ml}$.; in this method only radiation values can be given. The range of measurements was the same for the two procedures; the dip counter method was found to have no advantage over the dry method (table 1 ).

\section{RESULTS}

All the rats employed in the experiments were of the same breed and were kept under identical conditions. Fifty per cent of the rats of our colony survive the age of 23.5 months; we have therefore designated as old animals rats more than 20 months old. The groups of old rats included in the present series of experiments were between 20 and 29 months of age. Parallel to the studies on the old animals, experiments were conducted with young animals aged 7 to 9 months.

The animals were studied in two series, the first during the summer period (May-June, 1954) and the second during the winter season (January, 1955): the results were similar in both series. Series I comprised 10 young ( 7 month old) and 12 old (24 month

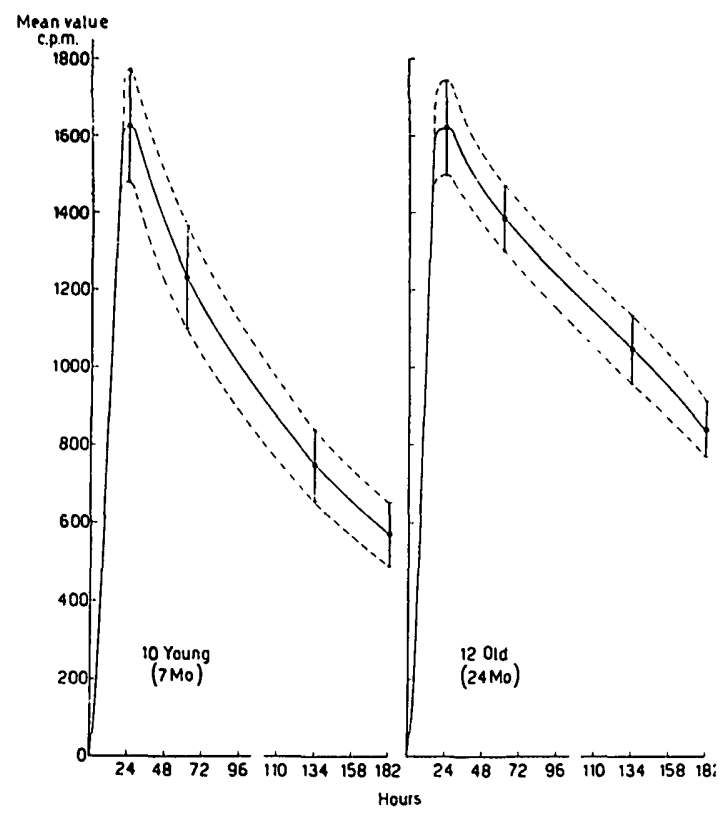

Fig. 1. Radiation measurements over the thyroid gland in rats following injections of 25 microcuries of $\mathrm{I}^{131}$ at zero time. Series I. Observations during summer period. old) rats; series II 20 young (7-9 month old) and 20 old (20-29 month old) animals.

The results of the radiation measurements over the thyroid gland were plotted in curves for each animal. The curves show individual differences which at first sight seem to raise considerable difficulties for comparing the $\mathrm{I}^{131}$ uptake and release. The comparison was simplified, however, when the values obtained on the same days after injection of $\mathrm{I}^{131}$ were correlated and the mean values computed. On the basis of single curves it was our impression that old animals often release $\mathrm{I}^{191}$ from the thyroid more slowly than the young rats, i.e., the curve becomes flat after a few days. However, not all the old animals reacted in the same way, and some of the young animals also exhibited flat curves. Possibly such animals should have been considered abnormal and excluded from the comparisons.

The mean values of the radioactivity measurements over the thyroid gland observed on the 1st, 3d, 5th, and 7th day after injection of $I^{131}$ are presented in table 2. The table

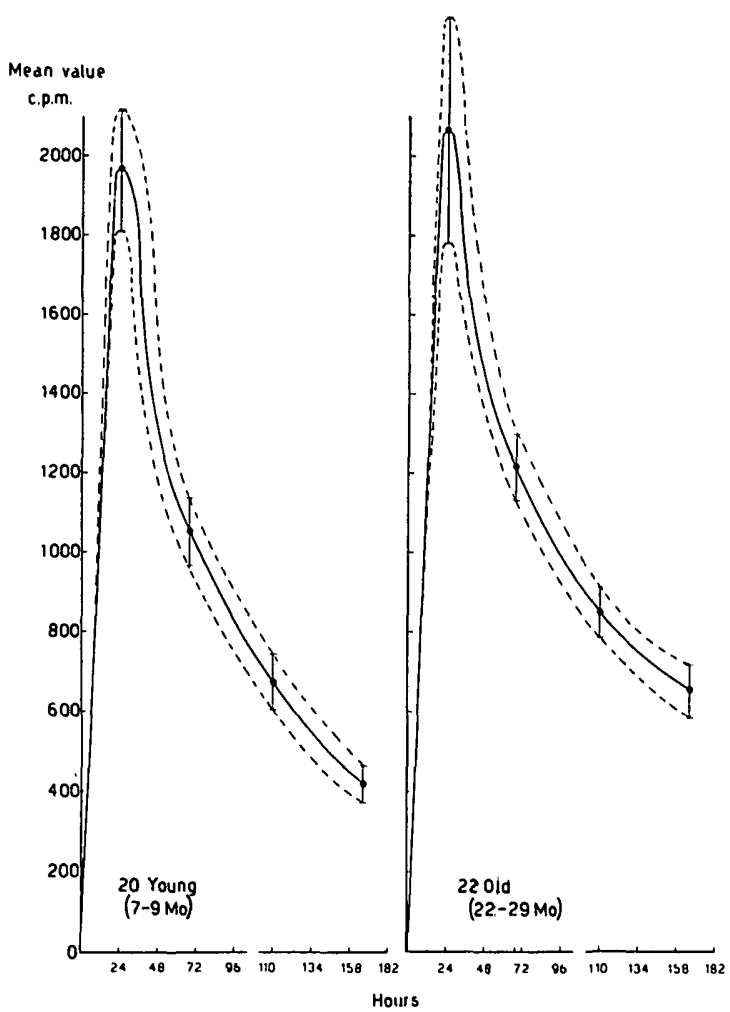

Fig. 2. Radiation measurements over the thyroid gland in rats following injections at 25 microcuries of $I^{131}$ at zero time. Series II. Observations during winter period. 
Table 2. Radioactivity Measurements Over Thyroid Gland of Rats at Various Times After Injection OF RADIOACTIVE IODINE.

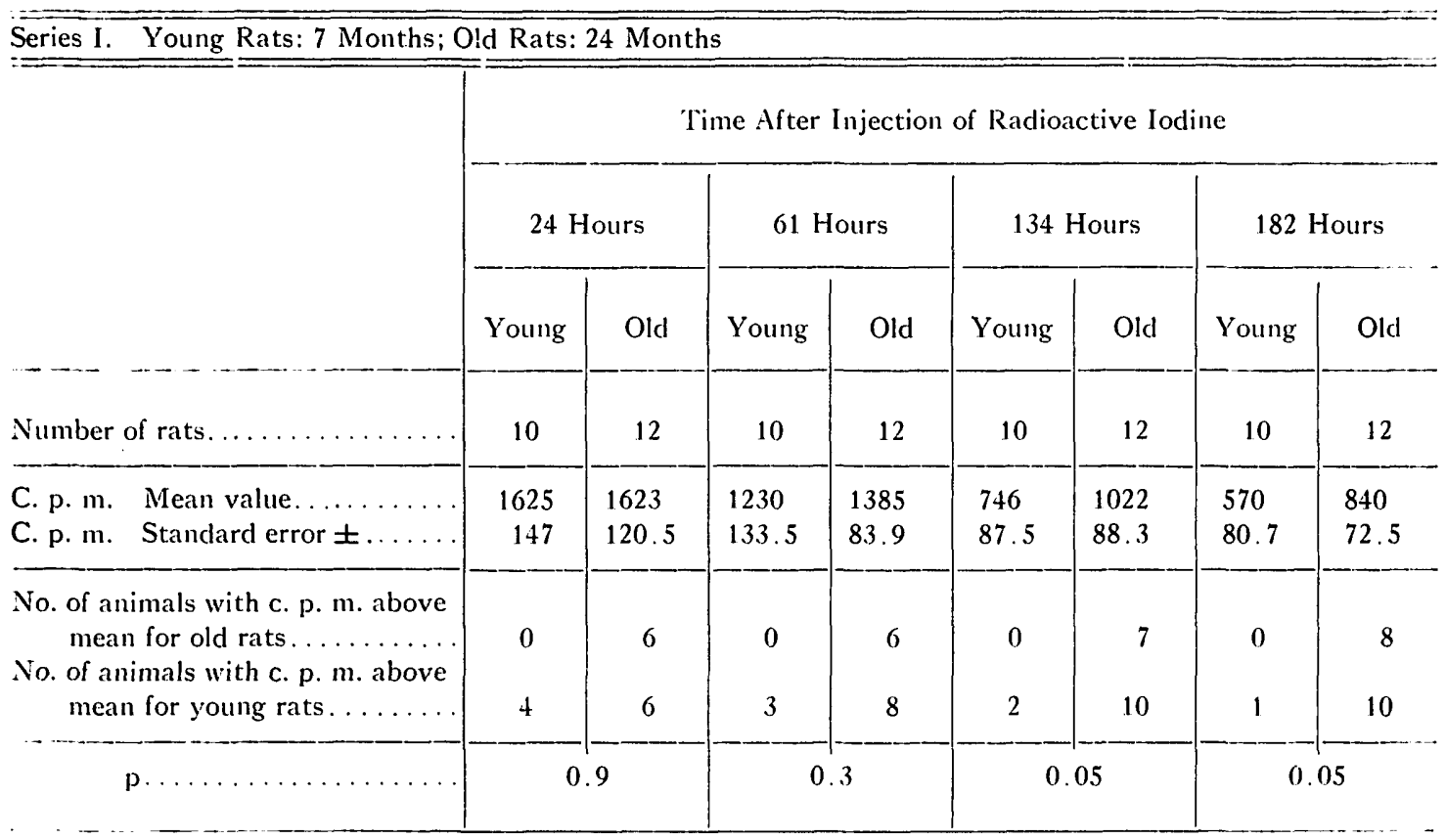

Series II. Young Rats: 7-9 Months; Old Rats: 20-29 Months

\begin{tabular}{|c|c|c|c|c|c|c|c|c|}
\hline & \multicolumn{2}{|c|}{$22-24$ Hours } & \multicolumn{2}{|c|}{69.71 Hours } & \multicolumn{2}{|c|}{ 110-114 Hours } & \multicolumn{2}{|c|}{165 Hours } \\
\hline & Young & Old & Young & Old & Young & Old & Young & Old \\
\hline Number of rats... & 20 & 22 & 20 & 20 & 20 & 20 & 20 & 20 \\
\hline $\begin{array}{l}\text { C. p. m. Mean value........... } \\
\text { C. p. m. Standard error } \pm \ldots \ldots \ldots\end{array}$ & $\begin{array}{r}1966 \\
155\end{array}$ & $\begin{array}{r}2067 \\
283\end{array}$ & $\begin{array}{r}1052 \\
85\end{array}$ & $\begin{array}{r}1216 \\
83\end{array}$ & $\begin{array}{r}672 \\
66.5\end{array}$ & $\begin{array}{r}851 \\
62\end{array}$ & $\begin{array}{l}419 \\
43.3\end{array}$ & $\begin{array}{r}657 \\
66\end{array}$ \\
\hline $\begin{array}{l}\text { No. of animals with c. p. m. above } \\
\text { mean for old rats .......... } \\
\text { No. of animals with c. p. m. above } \\
\text { mean for young rats....... }\end{array}$ & 0 & 5 & 0 & 14 & 0 & 17 & 10 & 17 \\
\hline p... & \multicolumn{2}{|c|}{0.7} & \multicolumn{2}{|c|}{0.1} & \multicolumn{2}{|c|}{0.05} & \multicolumn{2}{|c|}{0.01} \\
\hline
\end{tabular}

further contains the calculated standard error and $\mathrm{p}$ values. Not all intermediate measurements had been included.

As seen from table 2 the mean values for the old animals recorded on the 5 th and 7 th day were found to be higher than those observed in the young rats. The calculated $p$ values are 0.05 and 0.01 , respectively, for the groups in the two series of experiments. A listing has further been made in table 2 of the number of old animals which showed higher values than the mean value for the old group and the number of young rats exhibiting values above the mean for the young group at the same time of estimation. If the values for the 32 old animals in both series are 
combined, it will be seen that 27 , or 84 per cent, showed higher values on the 5 th and 7th day than the average value for the young animals measured at the same time.

In figures 1 and 2 these mean values together with their standard errors are shown graphically for the two series of animals. It is evident from the figures that the release of $I^{131}$ is slower in the old than in the young animals.

In order to evaluate these findings a consideration of the renal excretion of $\mathrm{I}^{131}$ seemed of importance. Such measurements, which were carried out in 15 old animals and 12 young animals in Series II showed the following: During the first 24 hours after the intraperitoneal injection of 25 microcuries of $\mathrm{I}^{131}$ very large quantities of iodine were excreted in the urine (table 3). Although some overlapping of the values for the groups occurred it was found that the young animals excreted much more iodine on the first day than did the old rats, namely an average of 48.4 per cent $( \pm 3.56)$ of the injected quantity compared with 29.2 per cent $( \pm 2.27)$ in the old animals. On the second day after injection the excretion became more or less constant and was only slightly less on the 5th and 6th days. The excretion on the second day was found to value about 5 per cent of the injected quantity of iodine and on the third day about 3 per cent. No characteristic difference in this steady excretion was noted between the old and the young animals. The sum of all $\mathrm{I}^{191}$ excretion during the first three days following the injection valued 57 per cent in the young and 38 per cent in the old animals (table 3). The total excretion over a period of 7 days was 68.1 per cent in the young and 50.9 per cent in the old rats.

\section{DISCUSSION}

The radioactive iodine, soon after it is concentrated by the thyroid gland, becomes bound as organic iodine in the form of thyroxine and triiodotyrosin. These hormones are released from the thvroid during the following days, and the $\mathrm{I}^{131}$ activity of the gland thus becomes a measure of the rate of their release. The results of the present investigation have revealed that the maiority of old rats ( 84 per cent) exhibit a delayed release of $\mathrm{I}^{131}$ from the thyroid gland as compared with young animals.
Table 3. Urinary Excretion of Radioactive Iodine in Percentage of Injected Dose of 25 Microcuries.

Figures represent individual animals.

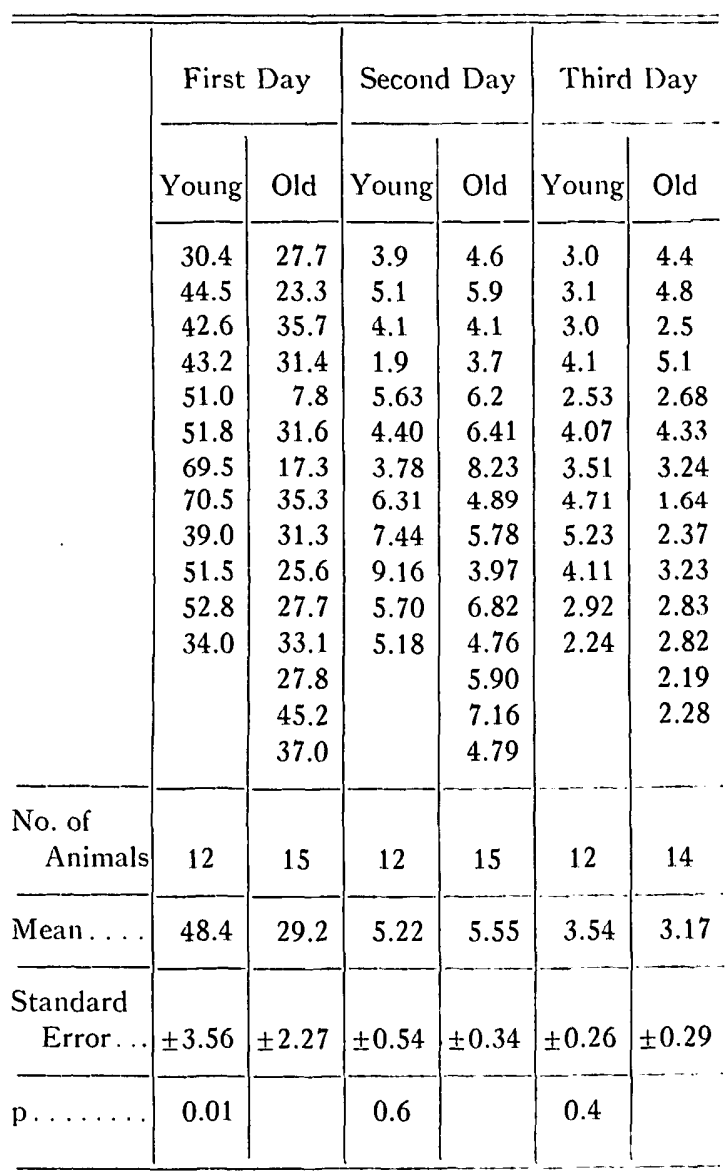

It was further found that old rats show a lower renal excretion of iodine during the first day after the iodine administration than do the young rats. This difference might be the result of an increased capacity of the thyroid of the old animals to retain iodine. The radioactivity measurements over the gland failed, however, to show an increased trapping of iodine by the thyroid in the old rats.

Another explanation of the lower iodine excretion by the old rats might be a reduced ability of the kidneys to excrete iodine. The quantities of iodine which are excreted in the urine are so small, however, that it is difficult to imagine that an impaired filtration by the kidneys could influence the excretion sig. 
nificantly. It seems more likely that the decreased excretion by the kidneys is also an expression of the diminished release of iodine from the thyroid gland in the aged animals; after the rapid fixation of the injected $\mathrm{I}^{131}$ by the thyroid a slow release will lead to a slower excretion of iodine in the urine.

The delayed release of the thyroid hormone in the old animals, as measured by $\mathrm{I}^{132}$, may be due primarily to a decreased metabolism of the body cells in the aged animals. Consequently, the thyroid would release less of its hormone, which increases the oxidation processes. Such explanation would agree with the well-known facts that in old age oxidation processes (2), body temperature and the upkeep of body temperature in cold surroundings (4), and the reaction of body temperature to diminished oxygen pressure (15) decrease. It may be of course that the decrease of cell metabolism is not the cause but rather the result of a decreased release of thyroid hormone. At present it seems hardly possible to decide definitely between these two possibilities.

\section{SUMMARY}

1. The activity of the thyroid gland was compared in 32 old (20-29 month) and 30 young (7-9 month) rats by measurement of the radioactivity of the gland following injection of $\mathrm{I}^{181}$.

2. The release of $I^{131}$ from the gland was in general found to be slower in the old than in the young animals. It was possible to demonstrate such difference in 84 per cent of the old rats on the fifth and seventh day after the injection.

3. The excretion of $I^{131}$ in the urine on the first day after injection valued 48.4 per cent of the injected quantity in the young rats and only 29.2 per cent in the old rats. The most probable explanation of this difference seems to be that the decreased release of $\mathrm{I}^{131}$ from the thyroid in the old rats is the cause of the lower urinary iodine excretion.

\section{REFERENCES}

1. Ackermann, P. G., and Iversen, K.: RadioIodine Excretion in the Aged. J. Gerontol., 8: 458-464, 1953.

2. Boothby, W., Berkson, J., and Dunn, H.: Studies of the Energy of Metabolism of Normal Individuals: A Standard for Basal Metabolism, with a Nomogram for Clinical Application. Am. J. Physiol., 116: 468-484, 1936.

3. Bonati, B., Salvi, A., and Rancati, G.: Sulla Funzionalità della Tiroide Senile. Gior. di Gerontol., 2: 182, 1954.

4. Cannon, W. B.: Problems of Ageing, 2nd ed. E. V. Cowdry, ed. William and Wilkins, Baltimore, 1942.

5. Cooper, E.R.H.: Histology of Endocrine Organs at Various Ages. Oxford University Press, Oxford, 1929.

6. Davies, D. F., and Shock, N. W.: Age Changes in Glomerular Filtration Rate, Effective Renal Plasma Flow, and Tubular Excretory Capacity in Adult Males. J. Clin. Investigation, 29: 496-507, 1950.

7. Kimble, S. T., and Stieglitz, E. J.: Hypothyroidism-a Geriatric Problem. Geriatrics, 7: 20-31, 1952.

8. Kountz, W. B., Chieff, M., and Kirk, J. E.: Serum Protein Bound Iodine and Age. J. Gerontol., 4: 132-135, 1949.

9. Lewis, W. H., and Alving, A. S.: Changes With Age in the Renal Function in Adult Men. Am. J. Physiol., 123: 500-510, 1938.

10. Mustacchi, P. O., and Loewenhaupt, E.: Senile Changes in the Histological Structure of the Thyroid Gland. Geriatrics, 5: 268-273, 1950.

11. Quimby, E. H., Werner, S. C., and Schmidt, C.: Influence of Age, Sex, and Season Upon Radioiodine Uptake by the Human Thyroid. Proc. Soc. Exper. Biol. Med., 75: 537-540, 1950.

12. Skanse, B.: Radioactive Iodine in the Diagnosis of Thyroid Disease. Acta med. Scandinav. Suppl. 235, 136: 1-186, 1949.

13. Verzár, F.: Control of Thyroid Activity with, $\mathrm{I}^{131}$ in the Rat. Radioisotope Technique, vol. I. Oxford University Press, Oxford, 1951, 1953.

14. Verzár, F., Sailer, E., and Vidovic, V.: Changes in Thyroid Activity at Low Atmospheric Pressures and at High Altitudes, as Tested with ${ }^{131}$ I. J. Endocrinol., 8: 308-320, 1952.

15. Verzár, F., and Flückiger, E.: Lack of Adaptation to Low Oxygen Pressure in Aged Animals. J. Gerontol., 10: 306-311, 1955. 